\title{
Depression, Anxiety and Stress among Saudi Arabian Dermatology Patients Cross-sectional study
}

"Anwar E. Ahmed, ${ }^{1,2}$ Abdulaziz M. Al-Dahmash, ${ }^{3}$ Qamra T. Al-Boqami, ${ }^{4}$ Yazeed F. Al-Tebainawi ${ }^{5}$

$$
\text { الاكتئاب والقلق والتوتر بين مرضى الأمراض الجللدية السعوديين }
$$

$$
\text { أنور أحمد، عبدالعزيز محمد الدهمش، قمراء البقمي، يزيد فارس التبيناوي }
$$

ABSTRACT: Objectives: This study aimed to determine the prevalence of depression, anxiety and stress among Saudi Arabian dermatology patients and to assess associations with sociodemographic and clinical characteristics. Methods: This cross-sectional study was conducted among 300 consecutive dermatology patients visiting King Abdulaziz Medical City in Riyadh, Saudi Arabia, in August 2015. The Arabic version of the Depression, Anxiety and Stress Scale was used to screen for symptoms of depression, anxiety and stress. Quality of life (QOL) was assessed using the Dermatology Life Quality Index. Results: A total of 254 dermatology patients participated in the study (response rate: $84.7 \%$ ). The prevalence of depression, anxiety and stress was $12.6 \%, 22.1 \%$ and $7.5 \%$, respectively. The presence of at least one of these negative emotional states was noted among $24.4 \%$ of the cohort (95\% confidence interval: $19.3-30.2 \%$ ). Depression was significantly higher among subjects who lacked family support (26.5\% versus $10.7 \% ; P=0.006)$ while anxiety was less common among patients who engaged in physical exercise $(14.5 \%$ versus $29.4 \% ; P=0.005)$. According to the multivariate logistic regression analysis, poor QOL and a lack of family support were significant predictors of a negative emotional state. Conclusion: Almost a quarter of the studied Saudi Arabian dermatology patients were found to suffer from at least one negative emotional state. A lack of family support and poor QOL were the primary factors associated with a negative emotional state. Interventional studies are needed to examine the effects of social and family support on psychological conditions among Saudi Arabian dermatology patients.

Keywords: Depression; Anxiety; Psychological Stress; Quality of Life; Social Support; Dermatology; Saudi Arabia.

الملخص: أهداف: هدفت هذه الدراسة إلى تحديد مدى انتشار الاكتئاب والقلق والتوتر لدى مدرئ مرضى الأمراض الجلدية السعوديين، وتقييم

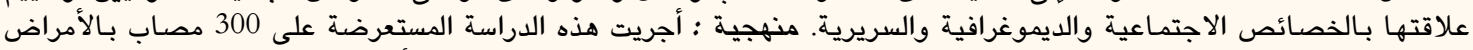

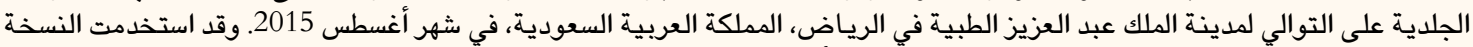

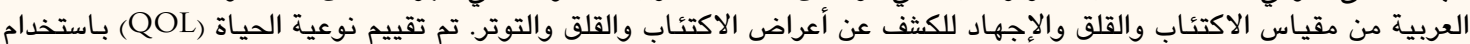

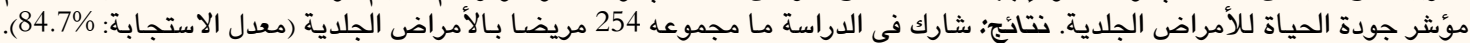

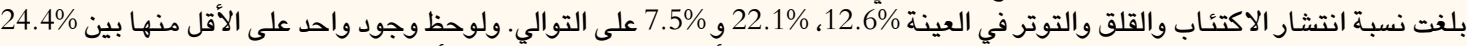

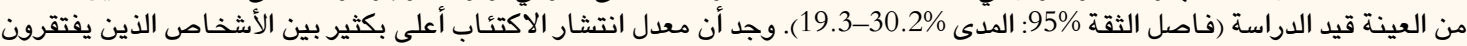

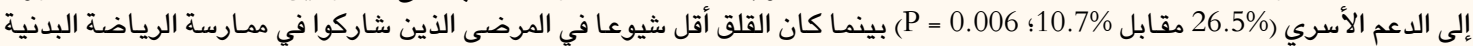

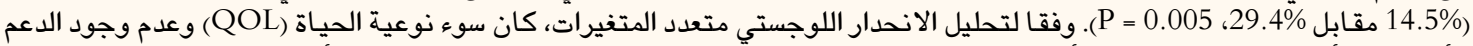

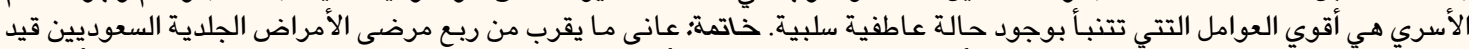

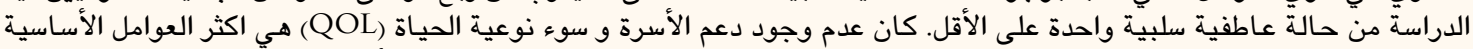

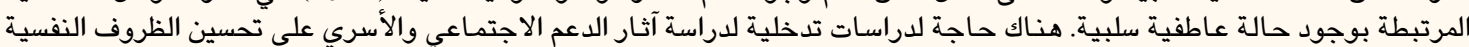
لدى مرضى الأمراض الجلدية السعوديين.

كلمات مفتاحية؛ الكآبة؛ القلق؛ الإجهاد النفسي؛ جودة الحياة؛ الدعم الأجتماعي؛ الأمراض الجلدية؛ العربية السعودية.

\section{AdVANCES IN KNOWLedge}

Little is known regarding the prevalence of depression, anxiety and stress among Saudi Arabian dermatology patients. The findings of this study indicated that 24.4\% of Saudi Arabian dermatology patients had at least one of these negative emotional states.

In this study, the primary factors associated with a negative emotional state were a lack of family support and poor quality of life (QOL).

\section{Application to Patient Care}

As almost a quarter of the studied Saudi Arabian dermatology patients were found to suffer from at least one negative emotional state, dermatology patients should be routinely screened for psychological symptoms, a lack of social/family support and poor QOL. Appropriate psychiatric counselling should then be provided as part of the dermatological treatment. 
$\mathrm{P}$ SYCHIATRIC OR PSYCHOLOGICAL FACTORS play a role in approximately $30 \%$ of dermatology disorders; stress, for example, can affect or exacerbate chronic skin diseases. ${ }^{1-3}$ An international multicentre cross-sectional study across 13 European countries found that $10.1 \%$ and $17.2 \%$ of dermatology patients suffered from depression and anxiety, respectively. When compared to healthy controls or the general population, dermatology patients are more likely to suffer from anxiety and depression; in a Norwegian study, $13 \%$ versus $3.7 \%$ and $5.8 \%$ versus $0.9 \%$ of dermatology patients versus controls suffered from anxiety and depression, respectively. ${ }^{5}$ Another study found the overall prevalence of depression and anxiety in patients with atopic dermatitis to be $15 \%$ and $12 \%$, respectively; in terms of gender, these negative emotional states were more prevalent in females. ${ }^{6}$ Another study explored the factors associated with psychiatric morbidity among 1,389 dermatological outpatients; the overall prevalence of psychiatric morbidity was $20.6 \%$, although female subjects with lesions on the face or hands had a greater prevalence over males. ${ }^{7}$ Other psychiatric disorders, such as suicidal ideation, also appear to be more common in dermatology patients in comparison to the general public. ${ }^{8,9}$ Anxiety levels and quality of life (QOL) have likewise been shown to be affected by dermatological disorders, with atopic dermatitis patients suffering from increased anxiety and a poorer QOL when compared to healthy individuals. ${ }^{10,11}$

Although psychological symptoms are common among dermatology patients, few relevant studies on this subject have been conducted among Arab populations. At the Khartoum Hospital in Sudan, Mufaddel et al. found that rates of depression and anxiety were higher among dermatology outpatients with acne, vitiligo, eczema and psoriasis compared with healthy controls. ${ }^{12}$ At the King Khalid University Hospital in Riyadh, Saudi Arabia, 29\% and 14\% of dermatology patients had anxiety and depression, respectively. ${ }^{13}$ Another study examined Arab vitiligo patients' beliefs and perceptions of their condition; $54 \%$ and $57 \%$ of the subjects reported feeling depressed or anxious, respectively. ${ }^{14}$ In the Qassim region of Saudi Arabia, 54.5\% of vitiligo patients were found to suffer from depression. ${ }^{15}$ As there has been little research conducted on this topic among Arab dermatology patients, this study aimed to assess depression, anxiety and stress among a sample of Saudi Arabian dermatology patients and to investigate associations with sociodemographic and clinical characteristics.

\section{Methods}

This cross-sectional survey was conducted among 300 consecutive outpatients visiting the Dermatology Outpatient Clinic at King Abdulaziz Medical City (KAMC) in Riyadh, Saudi Arabia, in August 2015. Only teenagers (14-17 years old) and adults ( $\geq 18$ years old) were included in the study. Patients who could not read or write Arabic were excluded. Based on the literature, the estimated prevalence of psychiatric morbidities among dermatology outpatients was set at $20.6 \% .^{7}$ In order to determine the prevalence among the study cohort with a precision of $5 \%$ and a 95\% confidence interval (CI), the required sample size was 252 subjects. Consequently, 300 KAMC dermatological patients were included in the study.

Demographic and clinical data (including age, gender, marital status, education level, employment status, income, physical activity level, smoker status, family support and the presence of specific dermatological conditions, obesity or hypertension) were collected from all participants. Depression, anxiety and stress were self-assessed by participants using an Arabic version of the 21-item Depression, Anxiety and Stress Scale (DASS-21). ${ }^{16,17}$ Each item had four possible responses (never, sometimes, often and almost always) represented by scores of $0,1,2$ and 3 , respectively. ${ }^{16,17}$ Participants were considered to have a negative emotional state if they suffered from at least one symptom of depression, anxiety or stress according to their questionnaire responses. Quality of life (QOL) was assessed using the validated Arabic version of the 10-item Dermatology Life Quality Index (DLQI). ${ }^{18,19}$ The DLQI is a self-administered tool which evaluates the impact of dermatological diseases on QOL. ${ }^{18,19}$ Items were scored on a four-point scale (range: $0-3$ ); a score of $<1$ was considered to indicate an adequate QOL. ${ }^{18,19}$

Data were analysed using the Statistical Package for the Social Sciences (SPSS), Version 22 (IBM Corp., Chicago, Illinois, USA). Demographic and clinical characteristics were reported descriptively. Prevalence rates of depression, anxiety and stress, as well as the prevalence rate of at least one of these negative emotional states, were reported with 95\% CIs. A Chi-squared test was used to analyse associations between categorical variables and negative emotional states. A $P$ value of $\leq 0.050$ was considered statistically significant and indicated an association through a bivariate analysis. A multivariate logistic regression model was used to study the associations between clinical or sociodemographic variables and negative 
emotional states. Adjusted odds ratios (aORs) were used to measure the strength of the associations between risk factors and negative emotional states.

This study was approved by the Institutional Review Board at the King Abdullah International Medical Research Center (\#RSS15/047).

\section{Results}

A total of 254 subjects participated in the study (response rate: $84.7 \%$ ). Of these, 59.8\% were female, $43.4 \%$ were employed and $40.0 \%$ were married. Only $17.7 \%$ of the subjects were teenagers while $82.3 \%$ were adults. Approximately half of the subjects did not engage in regular physical activity (50.2\%), 22.5\% were obese, $11.7 \%$ were hypertensive and $8.5 \%$ were smokers. More than half of the subjects (51.3\%) had a university degree. A total of $23.6 \%$ reported a lack of family support. The majority of the subjects had acne vulgaris (29.5\%), followed by atopic dermatitis (22.3\%), vitiligo (20.7\%) and psoriasis (6.4\%); the remainder had other diseases such as alopecia areata, lichen planus or warts.

Prevalenceratesofdepression, anxietyandstresswere 12.6\% (95\% CI: 8.8-17.3\%), 22.1\% (95\% CI: 17.1-27.7\%) and $7.5 \%$ (95\% CI: 4.6-11.4\%), respectively. The prevalence of at least one of these negative emotional states was $24.4 \%$ (95\% CI: 19.3-30.2\%). Table 1 presents rates of depression, anxiety, stress or at least one of these negative emotional states in relation to demographic and clinical data. Depression was significantly more common among subjects who reported a lack of family support in comparison to those reporting sufficient family support (26.5\% versus 10.7\%; $P=0.006$ ). Those with poor QOL were also significantly more likely to be depressed compared to those with adequate QOL (15.6\% versus $1.9 \%$; $P=0.007)$. Anxiety was significantly less common among subjects who engaged in regular physical exercise compared to those who did not (14.4\% versus 29.4\%; $P=0.005)$ and among non-obese compared to obese subjects (18.7\% versus $33.3 \%$; $P=0.037)$. Participants with sufficient family support were significantly less likely to be stressed than those without family support (6.3\% versus $16.3 \%$; $P=0.041$ ), while those with poor QOL were significantly more likely to be stressed than those with adequate QOL (9.6\% versus $0.0 \% ; P=0.016$ ). Subjects engaging in regular physical activity compared to those who did not regularly exercise $(16.8 \%$ versus $31.8 \% ; P=0.006)$ and those with family support compared to those without (22.6\% versus $38.8 \% ; P=0.025$ ) were significantly less likely to have at least one negative emotional state.
No significant associations were found between negative emotional states and other demographic or clinical characteristics.

After controlling for clinical and sociodemographic variables, the multivariate logistic regression model revealed that only poor QOL was significantly associated with the presence of at least one negative emotional state. The odds of suffering from at least one negative emotional state were 3.5 times higher in subjects with poor QOL compared to those with an adequate QOL (aOR: 3.5, 95\% CI: $1.1-11.5 ; P=0.039$ ). Sufficient family support was negatively associated with the risk of at least one negative emotional state (aOR: 0.3, 95\% CI: 0.1-0.8; $P=0.013$ ). Although the effect of gender was not significant, the presence of at least one negative emotional state occurred 2.9 times more frequently in females than in males (aOR: 2.9 , 95\% CI: 1.0-8.4; $P=0.057$ ) [Table 2].

\section{Discussion}

Prevalence rates of depression, anxiety and stress among Saudi Arabian dermatological patients in the current study were similar to a previous study investigating psychological disorders among dermatology patients. ${ }^{1}$ However, other local studies have reported much higher rates of depression and anxiety in dermatology patients. ${ }^{13-15}$ One possible reason for this discrepancy in prevalence rates may be the use of different assessment tools. For example, the study conducted in the Qassim region used the Beck Depression Scale, while the current study used the DASS-21. ${ }^{15}$ Mina et al. reported differences in levels of anxiety and depression between males and females. ${ }^{6}$ Although gender differences were not significant in the current study, negative emotional states nevertheless occurred 2.9 times more frequently among females.

Certain studies have indicated a link between the type of dermatological disorder and the presence of depression, anxiety or stress. An international multicentre observational cross-sectional study found that patients with psoriasis, atopic dermatitis, hand eczema and leg ulcers had the highest prevalence of depression and anxiety among dermatology patients. ${ }^{4}$ Another study also found a relationship between negative emotional states and types of skin disease; patients suffering from hair loss had the highest combined scores of anxiety and depression while those with psoriasis had the highest depression scores. ${ }^{13}$ Sharma et al. found evidence of depression in $23.3 \%$ of psoriasis patients and $10 \%$ in vitiligo patients. ${ }^{20}$ A recent review of the literature reported the prevalence of depression in psoriasis patients 
Table 1: Prevalence of depression, anxiety and stress* according to sociodemographic and clinical characteristics among Saudi Arabian dermatology patients $(\mathrm{N}=254)$

\begin{tabular}{|c|c|c|c|c|c|c|c|c|c|}
\hline \multirow[t]{3}{*}{ Characteristic $^{\dagger}$} & \multirow{3}{*}{$\begin{array}{c}\text { Overall, } \\
\text { n (\%) }\end{array}$} & \multicolumn{8}{|c|}{ Negative emotional state } \\
\hline & & \multicolumn{2}{|c|}{$\begin{array}{c}\text { Depression } \\
\quad(\mathrm{n}=32)\end{array}$} & \multicolumn{2}{|c|}{$\begin{array}{l}\text { Anxiety } \\
(\mathrm{n}=56)\end{array}$} & \multicolumn{2}{|c|}{$\begin{array}{c}\text { Stress } \\
(\mathrm{n}=19)\end{array}$} & \multicolumn{2}{|c|}{$\begin{array}{l}\text { At least one } \\
\quad(n=62)\end{array}$} \\
\hline & & n (\%) & $P$ value & n (\%) & $P$ value & n (\%) & $P$ value & n (\%) & $P$ value \\
\hline Gender & & & 0.272 & & 0.166 & & 0.770 & & 0.131 \\
\hline Male & $102(40.2)$ & $10(9.8)$ & & $18(17.7)$ & & $7(6.9)$ & & 19 (18.6) & \\
\hline Female & $152(59.8)$ & $22(14.5)$ & & $38(25.0)$ & & $12(7.9)$ & & $43(28.3)$ & \\
\hline Age & & & 0.188 & & 0.249 & & 0.999 & & 0.256 \\
\hline Teenager & $44(17.7)$ & $3(6.8)$ & & 7 (15.9) & & $3(6.8)$ & & $8(18.2)$ & \\
\hline Adult & $205(82.3)$ & $29(14.2)$ & & $49(23.9)$ & & $16(7.8)$ & & $54(26.3)$ & \\
\hline Marital status & & & 0.757 & & 0.421 & & 0.845 & & 0.952 \\
\hline Unmarried & $150(60.0)$ & $20(13.3)$ & & $31(20.7)$ & & $11(7.3)$ & & $37(24.7)$ & \\
\hline Married & $100(40.0)$ & $12(12.0)$ & & $25(25.0)$ & & $8(8.0)$ & & $25(25.0)$ & \\
\hline Education level & & & 0.324 & & 0.326 & & 0.405 & & 0.706 \\
\hline High school or less & $116(48.7)$ & $13(11.2)$ & & $30(25.9)$ & & $11(9.5)$ & & $31(26.7)$ & \\
\hline University & $122(51.3)$ & 19 (15.6) & & $25(20.5)$ & & $8(6.6)$ & & 30 (24.6) & \\
\hline Employment status & & & 0.938 & & 0.163 & & 0.729 & & 0.340 \\
\hline Employed & $106(43.4)$ & $13(12.3)$ & & $28(26.4)$ & & $9(8.5)$ & & $30(28.3)$ & \\
\hline Unemployed & $64(26.2)$ & $9(14.0)$ & & $16(25.0)$ & & $5(7.8)$ & & $17(26.6)$ & \\
\hline Student & $74(30.3)$ & $10(13.5)$ & & $11(14.9)$ & & $4(5.4)$ & & $14(18.9)$ & \\
\hline Income in SR & & & 0.384 & & 0.364 & & 0.802 & & 0.379 \\
\hline None & $83(35.6)$ & $10(12.1)$ & & $16(19.3)$ & & $6(7.2)$ & & $18(21.7)$ & \\
\hline$<10,000$ & $114(48.9)$ & 19 (16.7) & & $31(27.2)$ & & $10(8.8)$ & & $34(29.8)$ & \\
\hline$\geq 10,000$ & $36(15.5)$ & $3(8.3)$ & & $7(19.4)$ & & $2(5.6)$ & & $8(22.2)$ & \\
\hline Regular physical activity & & & 0.362 & & $0.005^{\ddagger}$ & & 0.840 & & $0.006^{\ddagger}$ \\
\hline Yes & $125(49.8)$ & 13 (10.4) & & $18(14.4)$ & & $9(7.2)$ & & $21(16.8)$ & \\
\hline No & $126(50.2)$ & $18(14.3)$ & & $37(29.4)$ & & $10(7.9)$ & & $40(31.8)$ & \\
\hline Smoker & & & 0.999 & & 0.425 & & 0.999 & & 0.236 \\
\hline Yes & $21(8.5)$ & $2(9.5)$ & & $3(14.3)$ & & $1(4.8)$ & & $3(14.3)$ & \\
\hline No & $227(91.5)$ & $30(13.2)$ & & $53(23.4)$ & & $18(7.9)$ & & $59(26.0)$ & \\
\hline Obese & & & 0.526 & & $0.037^{\dagger}$ & & 0.768 & & 0.143 \\
\hline Yes & $45(22.5)$ & $5(11.1)$ & & $15(33.3)$ & & $3(6.7)$ & & $15(33.3)$ & \\
\hline No & $155(77.5)$ & $23(14.8)$ & & $29(18.7)$ & & $14(9.0)$ & & $35(22.6)$ & \\
\hline Hypertensive & & & 0.392 & & 0.484 & & 0.999 & & 0.722 \\
\hline Yes & $29(11.7)$ & $2(6.9)$ & & $8(27.6)$ & & $2(6.9)$ & & $8(27.6)$ & \\
\hline No & $220(88.4)$ & $30(13.6)$ & & $48(21.8)$ & & $17(7.7)$ & & $54(24.6)$ & \\
\hline Family support & & & $0.006^{\ddagger}$ & & 0.086 & & $0.041^{\ddagger}$ & & $0.025^{\ddagger}$ \\
\hline Yes & $159(76.4)$ & $17(10.7)$ & & $33(20.8)$ & & $10(6.3)$ & & $36(22.6)$ & \\
\hline No & 49 (23.6) & $13(26.5)$ & & 16 (32.7) & & $8(16.3)$ & & $19(38.8)$ & \\
\hline
\end{tabular}




\begin{tabular}{|c|c|c|c|c|c|c|c|c|c|}
\hline Type of skin disease & & & 0.516 & & 0.124 & & - & & 0.189 \\
\hline Psoriasis & $16(6.4)$ & $3(18.8)$ & & $3(18.8)$ & & $1(6.3)$ & & $3(18.8)$ & \\
\hline Vitiligo & $52(20.7)$ & $5(9.6)$ & & $7(13.5)$ & & $4(7.7)$ & & $8(15.4)$ & \\
\hline Atopic dermatitis & $56(22.3)$ & $6(10.7)$ & & $12(21.4)$ & & $4(7.1)$ & & 14. (25.0) & \\
\hline Acne vulgaris & 74. (29.5) & $13(17.6)$ & & $24(32.4)$ & & $9(12.2)$ & & $25(33.8)$ & \\
\hline Other & $53(21.1)$ & $5(9.4)$ & & $10(18.9)$ & & $1(1.9)$ & & $12(22.6)$ & \\
\hline $\mathrm{QOL}^{\S}$ & & & $0.007^{\ddagger}$ & & 0.067 & & $0.016^{\ddagger}$ & & 0.062 \\
\hline Poor & $199(78.7)$ & $31(15.6)$ & & $49(24.6)$ & & $19(9.6)$ & & $54(27.1)$ & \\
\hline Adequate & $54(21.3)$ & $1(1.9)$ & & $7(13.0)$ & & $0(0.0)$ & & $8(14.8)$ & \\
\hline
\end{tabular}

Table 2: Sociodemographic and clinical factors influencing negative emotional states* among Saudi Arabian dermatology patients $(\mathrm{N}=254)$

\begin{tabular}{|c|c|c|c|c|c|c|c|c|}
\hline \multirow[t]{2}{*}{ Factor } & \multirow[t]{2}{*}{ Reference } & \multirow[t]{2}{*}{ B } & \multirow[t]{2}{*}{ SE } & \multirow[t]{2}{*}{ Wald } & \multirow[t]{2}{*}{$P$ value } & \multirow[t]{2}{*}{ aOR } & \multicolumn{2}{|c|}{$95 \%$ CI } \\
\hline & & & & & & & Lower & Upper \\
\hline Female & Male & 1.0 & 0.5 & 3.6 & 0.057 & 2.9 & 1.0 & 8.4 \\
\hline Adult & Teenager & 0.6 & 1.0 & 0.4 & 0.526 & 1.9 & 0.3 & 13.7 \\
\hline Married & Unmarried & -0.4 & 0.5 & 0.5 & 0.470 & 0.7 & 0.3 & 1.9 \\
\hline University-educated & High school education or less & -0.8 & 0.6 & 1.9 & 0.169 & 0.4 & 0.1 & 1.4 \\
\hline Employed & Student & 0.6 & 0.7 & 1.0 & 0.326 & 1.9 & 0.5 & 7.0 \\
\hline Unemployed & Student & -0.3 & 0.8 & 0.2 & 0.688 & 0.7 & 0.2 & 3.3 \\
\hline Income $<10,000 \mathrm{SR}$ & No income & 0.3 & 0.6 & 0.3 & 0.585 & 1.4 & 0.4 & 4.5 \\
\hline Income $\geq 10,000 \mathrm{SR}$ & No income & 0.3 & 0.9 & 0.1 & 0.770 & 1.3 & 0.2 & 7.5 \\
\hline Physical activity & No physical activity & -0.3 & 0.4 & 0.4 & 0.526 & 0.8 & 0.3 & 1.7 \\
\hline Smoker & Non-smoker & 0.2 & 0.9 & 0.1 & 0.820 & 1.2 & 0.2 & 6.9 \\
\hline Obese & Not obese & 0.4 & 0.5 & 0.7 & 0.398 & 1.6 & 0.6 & 4.3 \\
\hline Hypertensive & Not hypertensive & -0.7 & 0.8 & 0.8 & 0.369 & 0.5 & 0.1 & 2.2 \\
\hline Family support & No family support & -1.2 & 0.5 & 6.1 & $0.013^{\dagger}$ & 0.3 & 0.1 & 0.8 \\
\hline Vitiligo & Psoriasis & -0.6 & 1.0 & 0.4 & 0.505 & 0.5 & 0.1 & 3.4 \\
\hline Atopic dermatitis & Psoriasis & -1.1 & 1.0 & 1.2 & 0.270 & 0.3 & 0.1 & 2.3 \\
\hline Acne vulgaris & Psoriasis & -0.2 & 0.9 & 0.0 & 0.863 & 0.9 & 0.2 & 5.0 \\
\hline Other skin disease & Psoriasis & -0.8 & 1.0 & 0.7 & 0.406 & 0.5 & 0.1 & 3.0 \\
\hline Poor $\mathrm{QOL}^{\ddagger}$ & Adequate $\mathrm{QOL}^{\ddagger}$ & 1.3 & 0.6 & 4.3 & $0.039^{\dagger}$ & 3.5 & 1.1 & 11.5 \\
\hline Constant & & -1.6 & 1.3 & 1.4 & 0.229 & 0.2 & - & - \\
\hline
\end{tabular}

$S E=$ standard error; $a O R=$ adjusted odds ratio; $C I=$ confidence interval; $S R=$ Saudi Arabian riyal; $Q O L=$ quality of life.

*Depression, anxiety and stress were self-assessed by participants using the Arabic version of the Depression, Anxiety and Stress Scale. ${ }^{16,17}{ }^{+}$Significant as a risk factor for a negative emotional state at $\alpha=0.05 .{ }^{\ddagger} Q O L$ was self-assessed by participants using the Arabic version of the Dermatology Life Quality Index. ${ }^{18,19}$ 
to be $10-62 \%{ }^{21}$ In another study, depression $(67 \%$ versus $12 \%$ ) and anxiety (45\% versus $18 \%$ ) rates were higher in psoriasis patients than a control group. ${ }^{11}$ Kurd et al. noted that the risk of being diagnosed with depression, anxiety or suicidal ideation was $39 \%$ higher in patients with psoriasis compared to healthy controls. ${ }^{22}$ However, no relationship was seen in the current study between negative emotional states and the type of dermatological disease.

The current study also assessed whether Saudi Arabian dermatology patients received sufficient family support. Lower levels of depression and stress were found among subjects with family support compared to those who had none. Another factor which contributed significantly to depression and stress among the studied Saudi Arabian dermatological patients was poor QOL. Considering these findings, the researchers recommend screening dermatology patients for psychological morbidities and including appropriate psychiatric counselling and QOL evaluations as part of standardised dermatological treatment and management. In addition, future intervention studies are necessary to examine the effects of social and family support on the frequency of depression, anxiety and stress among Saudi Arabian dermatology patients.

There are several limitations to the current study. First, the findings are based on a cross-sectional assessment in which associations do not indicate causation. Second, the study relies on self-reported responses to the DASS-21 questionnaire and not on clinical diagnoses. Third, a healthy control group was not included in this study to determine the overall rate of negative emotional states in the general Saudi Arabian population.

\section{Conclusion}

Almost a quarter of the studied Saudi Arabian dermatology patients were found to suffer from at least one negative emotional state, including depression, anxiety or stress. A lack of family support and poor QOL were significantly associated with a negative emotional state among the subjects. As such, further research is needed to investigate the effects of QOL and social and family support on psychological morbidities among Saudi Arabian dermatology patients. Screening for psychological symptoms should be carried out among all dermatology patients and appropriate psychiatric counselling should be provided as required.

\section{CONFLICT OF INTEREST}

The authors declare no conflicts of interest.

\section{References}

1. Gupta MA, Gupta AK. Psychiatric and psychological comorbidity in patients with dermatologic disorders: Epidemiology and management. Am J Clin Dermatol 2003; 4:833-42. doi: 10.2165/00128071-200304120-00003.

2. Jafferany M. Psychodermatology: A guide to understanding common psychocutaneous disorders. Prim Care Companion I Clin Psychiatry 2007; 9:203-13. doi: 10.4088/PCC.v09n0306.

3. Osman OT, Mufaddel A, Almugaddam F, Augusterfer EF. The psychiatric aspects of skin disorders. Expert Rev Dermatol 2011; 6:195-209. doi: 10.1586/edm.11.10.

4. DalgardFJ, Gieler U, Tomas-Aragones L, Lien L, PootF, Jemec GB, et al. The psychological burden of skin diseases: A crosssectional multicenter study among dermatological out-patients in 13 European countries. J Invest Dermatol 2015; 135:984-91. doi: $10.1038 /$ jid.2014.530.

5. Balieva F, Lien L, Kupfer J, Halvorsen JA, Dalgard F. Are common skin diseases among Norwegian dermatological outpatients associated with psychological problems compared with controls? An observational study. Acta Derm Venereol 2016; 96:227-31. doi: 10.2340/00015555-2200.

6. Mina S, Jabeen M, Singh S, Verma R. Gender differences in depression and anxiety among atopic dermatitis patients. Indian J Dermatol 2015; 60:211. doi: 10.4103/0019-5154.152564.

7. Picardi A, Abeni D, Renzi C, Braga M, Puddu P, Pasquini P. Increased psychiatric morbidity in female outpatients with skin lesions on visible parts of the body. Acta Derm Venereol 2001; 81:410-4. doi: 10.1080/000155501317208345.

8. Hughes JE, Barraclough BM, Hamblin LG, White JE. Psychiatric symptoms in dermatology patients. Br J Psychiatry 1983; 143:51-4. doi: 10.1192/bjp.143.1.51.

9. Dieris-Hirche J, Gieler U, Kupfer JP, Milch WE. [Suicidal ideation, anxiety and depression in adult patients with atopic dermatitis]. Hautarzt 2009; 60:641-6. doi: 10.1007/s00105-0091744-y.

10. Linnet J, Jemec GB. An assessment of anxiety and dermatology life quality in patients with atopic dermatitis. Br J Dermatol 1999; 140:268-72. doi: 10.1046/j.1365-2133.1999.02661.x.

11. Golpour M, Hosseini SH, Khademloo M, Ghasemi M, Ebadi A, Koohkan F, et al. Depression and anxiety disorders among patients with psoriasis: A hospital-based casecontrol study. Dermatol Res Pract 2012; 2012:381905. doi: 10. $1155 / 2012 / 381905$

12. Mufaddel A, Abdelgani AE. Psychiatric comorbidity in patients with psoriasis, vitiligo, acne, eczema and group of patients with miscellaneous dermatological diagnoses. Open J Psychiatr 2014; 4:168-75. doi: 10.4236/ojpsych.2014.43022.

13. AlShahwan MA. The prevalence of anxiety and depression in Arab dermatology patients. J Cutan Med Surg 2015; 19:297-303. doi: 10.2310/7750.2014.14110.

14. AlGhamdi KM. Beliefs and perceptions of Arab vitiligo patients regarding their condition. Int J Dermatol 2010; 49:1141-5. doi: $10.1111 /$ j.1365-4632.2010.04514.x

15. Al-Harbi M. Prevalence of depression in vitiligo patients. Skinmed 2013; 11:327-30.

16. Antony MM, Bieling PJ, Cox BJ, Enns MW, Swinson RP Psychometric properties of the 42-item and 21-item versions of the Depression Anxiety Stress Scales in clinical groups and a community sample. Psychol Assess 1998; 10:176-81. doi: 10.1037/1040-3590.10.2.176.

17. Taouk M, Lovibond PF, Laube R. Psychometric properties of an Arabic version of the Depression Anxiety Stress Scales (DASS). From: www2.psy.unsw.edu.au/dass/Arabic/Arabic\%20 DASS\%20Report.doc Accessed: Dec 2015. 
18. Finlay AY, Khan GK. Dermatology Life Quality Index (DLQI): A simple practical measure for routine clinical use. Clin Exp Dermatol 1994; 19:210-16. doi: 10.1111/j.1365-2230.1994. tb01167.x.

19. Khoudri I, Lamchahab FZ, Ismaili N, Senouci K, Hassam B, Abouqal R. Measuring quality of life in patients with psoriasis using the Arabic version for Morocco of the Dermatology Life Quality Index. Int J Dermatol 2013; 52:795-802. doi: 10.1111/j.1365-4632.2011.05450.x.
20. Sharma N, Koranne RV, Singh RK. Psychiatric morbidity in psoriasis and vitiligo: A comparative study. J Dermatol 2001; 28:419-23. doi: 10.1111/j.1346-8138.2001.tb00003.x.

21. Chamoun A, Goudetsidis L, Poot F, Bourdeaud'hui F, Titeca G. [Psoriasis and depression]. Rev Med Brux 2015; 36:23-8.

22. Kurd SK, Troxel AB, Crits-Christoph P, Gelfand JM. The risk of depression, anxiety, and suicidality in patients with psoriasis: A population-based cohort study. Arch Dermatol 2010; 146:891-5. doi: 10.1001/archdermatol.2010.186. 